Revista de Antropología Social

ISSN: 1131-558X

\title{
Las múltiples formas de lo urbano y la experiencia del universalismo
}

Ángel Díaz de Rada ${ }^{1}$

CRUCES, Francisco (Coord.). 2016. Cosmópolis. Nuevas maneras de ser urbanos. Barcelona: Gedisa.

En el capítulo introductorio de este libro, al referirse a uno de los problemas metodológicos centrales que ha de abordar el estudio de cualquier ciudad, Francisco Cruces escribe: "Al no existir un relato único desde el que construir el todo, se hace necesario un montaje complejo de puntos de vista" (17).

La antropología social y cultural goza aún de una imagen pública equívoca, como ciencia ocupada en gran medida en hacer visible lo alterno y lo extraño. Sin embargo, algo paradójicamente, lo aparentemente inmediato, propio y conocido, que conforma la ciudad exige también un considerable trabajo de visibilización. Por tomar solo dos imágenes de Cosmópolis, se hace necesario visibilizar los flujos aparentemente intangibles de capitales e información, como en el capítulo 2 escrito por Romina Colombo; o visibilizar los múltiples movimientos en el mercado de abastecimiento alimentario, como en el capítulo 5 de Montserrat Cañedo.

Un objeto central en ese proceso de visibilización es sin duda el ritmo, los ritmos, como fue formulado por Lefèbvre en una aproximación poco más que intuitiva: Rhythmanalysis ${ }^{2}$. Cosmópolis apunta muchas claves para pensar sobre ese objeto fundamental de la ciudad y lo urbano, que tal vez podrían ser recogidas en indagaciones posteriores. Al sugerirlo, me pongo en la posición del lector que ha encontrado en este libro motivos para pensar.

La estructura de Cosmópolis es reticular. A esa estructura conduce, bajo mi punto de vista, cualquier planteamiento multisituado. Los autores han decidido entender esa red como un conjunto de "ventanas" para mirar la ciudad; una metáfora que deja intencionadamente al lector la tarea de establecer las múltiples relaciones entre las perspectivas de lo urbano que esas ventanas aportan.

Tras el Madrid en cifras y en perspectiva histórica de Romina Colombo, donde no se pretende ofrecer una descripción "en la superficie de las capas del presente, sino en el espesor de las capas del pasado" (72) (capítulo 2), se ofrece la siguiente red de nodos (algunos de ellos también formados por otros nodos). El estudio que Fernando Monge ofrece en el capítulo 3 está compuesto como una crónica de dos (o tal vez más) barrios en uno, tomando por objeto a "Maravillas-Malasaña-Universidad". El capítulo 4, escrito por Luis Reygadas, se centra en el análisis de cuatro empresas emergentes en la ciudad de Madrid. Montserrat Cañedo presenta en el capítulo 5

Universidad Nacional de Educación a Distancia (UNED)

2 Henri Lefebvre, 2004 (1992), Rhythmanalysis. Space, time and everyday life. London: Continuum. 
las lógicas de acción en Mercamadrid, bajo la imagen económica (es decir, sociomoral) del "precio justo". En el capítulo 6, Sara Sama presenta su investigación de la génesis y formación de un huerto comunitario y sus objetivaciones en la Internet. El capítulo 7, a cargo de Fernando González de Requena, toma por objeto las prácticas en el hacktivismo del software libre. Las dinámicas musicales en la ciudad de Madrid son el objeto del capítulo 8, escrito por Héctor Fouce. En el capítulo 9, Gloria Durán se ocupa de los espacios emergentes del arte en Madrid durante las últimas décadas. Karina Boggio explora la emergencia del Madrid multiétnico en el capítulo 10, así como las múltiples trayectorias de ida y vuelta de los migrantes. El libro se cierra con la investigación de Francisco Cruces sobre intimidades en contexto urbano.

Esa estructura multisituada y reticular es ya una imagen de uno de los replanteamientos centrales de este libro: el replanteamiento de la noción de local. ¿Cómo debemos entender, hoy, lo local? En Cosmópolis se menciona una posibilidad, que toma como referencia a Featherstone: la "ruptura de la localidad" (72). Esta idea, rompedora, como se indica en la expresión, al estilo de una retórica que es muy común en la literatura de las últimas décadas sobre la "modernidad", no ha sido siempre bien entendida. Ruptura no significa ahí quiebra, degradación o desaparición; sino, más bien, rotura, estallido o desbordamiento, en el sentido metodológico de que, para cualquier local, los materiales empíricos acotados en su territorialización son manifiestamente insuficientes.

Roto y desbordado, lo local está ahí, de todos modos, presente y desafiante; y la lección fundamental de este libro es su radical problematización. De lo que se trata es de la radical problematización de lo local, y de los efectos factuales de las prácticas locales en muy diversas escalas y con muy diversos alcances. Tal como se muestra en Cosmópolis, lo local no puede ser tratado como una idea de sentido común. Un ejemplo, entre las decenas que ofrece el libro: los locales que Fernando Monge denomina de "sociabilidad aumentada", espacios "de interacción personal que combinan la presencia física con la que ofrecen las redes sociales, la telefonía e Internet" (101).

Un segundo problema fundamental que me ha suscitado la lectura de este libro, y que tiene desde luego una trayectoria de largo recorrido en ciencias sociales se encierra en la caracterización analítica de lo urbano. Llevo algunos meses enfrascado en la obra monumental de Fernand Braudel sobre la modernidad: los tres volúmenes de Civilización y Capitalismo entre los siglos XV y XVIII. Especialmente en el primer volumen de esta obra, pero con resonancias evidentes en el conjunto, Braudel ilustra con un detalle fascinante una de las piezas esenciales de lo que hemos dado en entender como "modernidad": el surgimiento de una forma de socialidad que se nucleó y se objetivó, especialmente a partir del siglo XII, en torno a las ciudades ${ }^{3}$. Ésa fue una transformación lenta que ocupó una buena parte del pasado milenio y que se apoyó en las progresivas tecnologías del urbanismo, y del transporte de los cuerpos y de las mercancías.

Cosmópolis - aún algo anclado a la idea tópica de ciudad como forma de lo urbano- abre múltiples fuentes de reflexión sobre un proceso que, iniciado con

Fernand Braudel,1985, The structures of everyday life. Civilization and capitalism 15th.-18th. centuries. Vol I, New York: Harper, especialmente las pp. 479 y ss. En relación con la problemática de la ciudad y lo urbano, veáse Michel de Certeau 1990 (1980), L’invention du quotidien. 1. Arts de faire, París: Gallimard, pp. 139 ss.; y sobre todo Henri Lefebvre, 1991 (1974), The production of space. Oxford: Blackwell. 
claridad durante los siglos XIX y XX, tal vez constituya, al consolidarse, una transformación análoga en el nuevo milenio que habitamos: la expansión de lo urbano con o sin ciudad. Es decir, la expansión del modo de socialidad que se generó en las ciudades, como topoi geográficos, a los recodos, los enclaves y los rincones que, hasta hace no más de cinco décadas, consideraríamos "periféricos", "rurales", etcétera. Esta transformación se está apoyando —además de en las tecnologías objetivadas en los siglos pasados - en la progresiva tecnología del transporte de los mensajes, las imágenes, los imaginarios, y los mundos de sentido, generadora a su vez de nuevas emergencias y expansiones de la estructuración social.

Para una lectura fructífera de este libro, sugiero entonces poner entre corchetes al designador topológico [Madrid]; ello permitirá subrayar las dimensiones de lo urbano, en el entorno de lo que a mi juicio constituye el núcleo de su genuina socialidad: la experiencia del vínculo universalista. Es decir, la experiencia de la vinculación con el — hasta entonces- desconocido ${ }^{4}$.

Sugiero también poner entre corchetes la idea de Ulf Hannerz sobre la noción de [cosmopolitismo] ("la voluntad de involucrarse con el otro"), que, por moralizante, puede llevarnos a ignorar que la vinculación con el desconocido - por ejemplo, en ese fantástico empeño urbano que tuvo su emergencia modélica en 1492 - puede conllevar precisamente, también, la posibilidad de la dominación, la explotación o el exterminio. Hay que tener en cuenta que las primeras ciudades europeas no surgieron como espacios nítidamente abiertos de socialización; más bien surgieron como constituyentes sociales para los que el cálculo de las pertenencias, del incluido y del excluido, se convirtió en tema dominante del espacio público; y como tal fue luego transferido, en otra escala, a los estados nacionales ${ }^{5}$.

En el centro de lo urbano, en cualquiera de sus objetivaciones prácticas, con ciudad o sin ella, se sitúa la emergencia de vínculos imprevistos. $\mathrm{O}$ más aún, el fomento y la protección de esos vínculos. Ello no solo constituye una experiencia política inicialmente contraintuitiva para las personas (como apuntó Gerd Baumann ${ }^{6}$ ), que han de responder a su condición de ciudadano universalista tanto $-\mathrm{y}$ en rigor más que - a su condición de madre, hijo, o "natural" (como cuando se dice "natural de Navalmoral"). Constituye también un enorme desafío para una disciplina la antropología social y cultural - que se formó, en su primer clasicismo, bajo la premisa de una sociedad compuesta de vínculos estructuralmente previsibles, normativamente orientados, estructurados, probabilísticamente limitados y "elementales"?: una ciencia de la periferia colonial de las colonias externas a los estados nacionales, y de la periferia rural de sus colonias internas. Para los que ahora se inician en esta ciencia, Cosmópolis puede contribuir de un modo algo brutal a romper esa imagen; para los que ya nos hemos iniciado, contribuye a replantear de un modo radical ese clasicismo. Al menos hoy $-\mathrm{y}$, si hemos de creer a Braudel, hace

4 Para un delineamiento empírico de la experiencia del universalismo o del universalismo de experiencia, véase Francisco Cruces y Ángel Díaz de Rada, 1996, La ciudad emergente. Transformaciones urbanas, campo político y campo asociativo en un contexto local. Madrid: UNED, p. 62.

Cf. Braudel, Op. Cit.

6 Werner Schiffauer, Gerd Baumann, Riva Kastoriano, y Steven Vertovec (Eds.), 2004, Civil enculturation. Nation-State, school and ethnic difference in The Netherlands, Britain, Germany and France, New York: Berghahn.

7 Claude Lévi-Strauss, 1985 (1949), Las estructuras elementales del parentesco. Barcelona: Planeta-De Agostini, 2 Vols. 
ya muchos siglos - esas periferias no albergan bajo ninguna perspectiva posible tales estructuras "elementales".

Como ilustra muy bien Cosmópolis, lo central es la poiesis y la incoación de sociedad y cultura ${ }^{8}$. Esa mente humana universal que imaginó Lévi-Strauss tomando por objeto un puñado de sociedades presumiblemente dotadas de "estructuras elementales", sucumbe ante otra prioridad humana que es, a mi modo de ver, más universal e incluyente: el ser humano, como agente, busca en todas partes «dar forma a la cotidianeidad" (37). O, como escribió una de las personas del huerto urbano de Sara Sama para referirse al espacio ocupado sobre el que iban a actuar: la mente humana, incluso cuando viene ya repleta de pasado, tiene ante sí "un espacio vacío lleno de posibilidades" (182).

O, en otra versión, esa noción de Kelty de "público recursivo", traída por Fernando González de Requena al estudiar el espacio del software libre: "un colectivo que además de gestionar contenidos propios se implica en desarrollar y sostener las infraestructuras que permiten su propia existencia como tal público" (209). O, en un paso más allá, en ese mismo estudio, al tratar del colectivo Comunes, un constituyente cuyo "objetivo no es constituirse y funcionar como un grupo o nodo de red en sí mismo, sino incidir en la constitución de redes y colectivos socio-técnicos".

En todo caso, siempre se trata de constituyentes sociales que objetivan su propia existencia ontológica como tales a través de la creación de objetos en el mundo: no son acciones funcionalmente subsidiarias de estructuras sociales, sino constituyentes sociales cuya forma vincular se genera en la creación de la acción y los objetos que se derivan de ella. Aquí la palabra clave, es, sin duda, creación.

En esos procesos, parece esencial a lo urbano lo que el propio Fernando González de Requena denomina "la lógica del hack" (225), cuyo supuesto fundamental es la noción de transformación: lo real puede ser cambiado, empezando por el self, con el hacerse uno a sí mismo y a su espacio-tiempo.

En relación con esto, hay, de fondo, dos problemas esenciales: en primer lugar, la dinámica de la legitimidad, es decir, los procesos de construcción de lo real; y, en segundo lugar, las coerciones que los estados de objetivación previos ejercen sobre esos actos de creación. Dicho de otro modo, el ser humano transforma lo real solo sobre la base de las formas ya existentes; y por eso no hay creación sin riesgo, ni agencia sin sujeción. No en vano la noción de jugada, que, según Fernando González de Requena caracteriza a la lógica del hacker (221), y que yo creo útil como síntesis de la acción específicamente urbana, es también la que usó Pierre Bourdieu en El sentido práctico, para referirse a la naturaleza básica de la práctica en estado práctico - enjeu .

La acción urbana es, marcadamente, jugada. Su espacio específico es el de la estructuración sin fin, hacia adelante; de ahí que resulte tan arriesgado ese espacio, y tan sencillo perderse en las ciudades; o, mejor dicho, en lo urbano. Este libro no ofrece un mapa para guiarse en ese espacio, sino una red de pescar en la que el buen lector se sacudirá agónicamente. En ello consiste su principal virtud. Disfrútenlo.

8 James W. Fernandez, 2006 (1982), "La oscuridad al fondo de la escalera. Lo incoado en la investigación simbólica y algunas estrategias para abordarlo", en En el dominio del tropo: Imaginación figurativa y vida social en España, Madrid: UNED, pp. 285-314. Véase también Michael Carrithers, 2005, "Anthropology as a Moral Science of Possibilities", Current Anthropology, 46 (3), pp. 433-456.

9 Pierre Bourdieu, 1991 (1980), El sentido práctico. Madrid: Taurus. A propósito de enjeu, véase la nota preliminar sobre la traducción, de Álvaro Pazos. 